\title{
BMJ Open Prevalence and factors associated with frailty among community-dwelling older people in rural Thanjavur district of South India: a cross-sectional study
}

\author{
Kirubakaran Kesavan Kendhapedi, Niveditha Devasenapathy
}

To cite: Kendhapedi KK, Devasenapathy N. Prevalence and factors associated with frailty among communitydwelling older people in rural Thanjavur district of South India: a crosssectional study. BMJ Open 2019;9:e032904. doi:10.1136/ bmjopen-2019-032904

- Prepublication history and additional material for this paper are available online. To view these files, please visit the journal online (http://dx.doi. org/10.1136/bmjopen-2019032904).

Received 11 July 2019 Revised 05 September 2019 Accepted 06 September 2019

Check for updates

(c) Author(s) (or their employer(s)) 2019. Re-use permitted under CC BY-NC. No commercial re-use. See rights and permissions. Published by BMJ.

Indian Institute of Public Health - Delhi, Public Health Foundation of India, Gurgaon, India

Correspondence to Kirubakaran Kesavan Kendhapedi;

karan.kendhapedi@gmail.com

\section{ABSTRACT}

Objective There is sparse data on the prevalence of frailty from rural parts of India. Our aim was to estimate prevalence of frailty among community-dwelling older people in rural South Indian population and explore sociodemographic factors associated with frailty. We further explored the associations between frailty with fear of falling and falls.

Design Community based cross-sectional study. Setting Four villages in Thanjavur district of Southern India.

Participants Random sample of adults aged 60 years and above from four villages.

Methods We sampled community-dwelling older adults from the electoral list of four villages using stratified random sampling. We report prevalence of frailty as defined by physical definition (Fried's Phenotype), accumulation of deficits (Frailty Index) and multi-domain definition (Tilburg Frailty Indicator). We report proportion of agreement of frailty status between the frailty tools. We used logistic regressions with robust SEs to examine the associations between socio-demographic determinants with frailty and the association between frailty with fear of falling and falls.

Results Among the 408 participants, the weighted (nonresponse and poststratification for sex) prevalence and $95 \% \mathrm{Cl}$ of frailty was $28 \%$ (18.9 to 28.1 ) for physical definition, $59 \%$ (53.9 to 64.3) for accumulation of deficits and $63 \%$ (57.4 to 67.6) for multi-domain definition. Frailty Index and Tilburg Frailty Indicator had good agreement (80\%). Age, female, lower education, lower socioeconomic status, minimum physical activity in routine work were independently associated with frailty irrespective of the frailty definitions. Frail elderly had higher odds of falls as well as fear of falling compared with non-frail, irrespective of the definitions.

Conclusion Prevalence of frailty among older people in rural Thanjavur district of South India was high compared with low-income and middle-income countries. Understanding the modifiable determinants of frailty can provide a valuable reference for future prevention and intervention.

\section{BACKGROUND}

Frailty is a dynamic multidimensional geriatric syndrome and its risk increases with age
Strengths and limitations of this study

We compared the prevalence of frailty measured using three definitions.

- Households were randomly sampled to minimise selection bias.

- Though the response rate was $60 \%$, there were no differences in the characteristics (age and gender) between responders and non-responders.

- Cognition, an important confounder of frailty was not adjusted in the analysis for Fried's Phenotype and Frailty Index models.

- Our sample comprised older adults from rural Southern India who predominately engage in agricultural activities.

and is characterised by higher vulnerability to external stressors. ${ }^{1}$ Frailty is conceptualised based on three definitions. Physical frailty definition considers frailty as 'a biological syndrome of decreased reserve and resistance to stressors resulting from decline across multiple physiological systems, and causing vulnerability to adverse outcomes'. ${ }^{1}$ The second definition deems frailty as the accumulation of the deficits from various domains including but not limited to physical health, cognition, self-rated health status and activities of daily living (ADLs). ${ }^{2}$ The third approach involves a multidimensional definition of frailty including physiological, psychological, cognition, nutrition and social domains. ${ }^{3}$ Different models of frailty due to their different theoretical construct yield varied prevalence estimates that pose a major challenge in comparing the results across different studies. ${ }^{5}$

Over the past decade, interest in frailty has substantially grown among geriatric researchers because of its predictive nature of death, hospitalisation and postoperative complications. ${ }^{6}$ Falls-related injuries or fractures are known to have an adverse health 
impact on the community dwelling frail older adults and are the leading cause of mortality and morbidity among such individuals. ${ }^{7}$ Since frailty is a reversible condition, early identification can help in averting falls and related complications among older adults. ${ }^{8}$ Community screening programmes can also be useful in preventing the adverse outcomes through group physical exercise programme, nutrition supplements, cognitive training or a combination of these. Such health interventions have been found effective in delaying frailty. ${ }^{9}$

India is witnessing an increase in the percentage of older adults due to the demographic transition. It is expected that the proportion of older adults would increase from $8 \%$ in 2015 to $19 \%$ in $2050 .{ }^{10}$ It is important to quantify the burden of frailty to inform policymakers on the evolving issues and the needs of the rising geriatric population. Previous studies from India have reported the prevalence of frailty that ranged from $11 \%$ to $58 \%$ using different frailty measurement tools. ${ }^{11-13}$ However, the prevalence of frailty in rural settings were unaddressed in these studies. Therefore, the main objective of this study was to measure and compare the prevalence of frailty among the rural South Indian population using tools from the three theoretical constructs of frailty. We explored the socio-demographic determinants of frailty among community-dwelling older people. We further explored the associations between frailty with fear of falling and falls.

\section{METHODS}

\section{Study setting and study population}

We conducted a cross-sectional study in four contiguous villages in Southern India. The average population in the selected villages was 17109 as per Census 2011 with almost equal sex ratio. We included older adults aged 60 years and above, permanently residing in the villages and were able to provide voluntary informed consent. We excluded older adults with terminal illness, bedridden or wheelchair bound, severe hearing or visual impairment and any acute illness at the time of the survey. We sought verbal approval from the community leaders of the respective villages for conduct of the study.

\section{Sample size estimation and sampling strategy}

We estimated sample size using Confidence Interval (CI) method in nMaster 2.0 software. The expected proportion of frailty was $57 \%$ as per accumulation of deficit definition. ${ }^{12} \mathrm{~A}$ total of 623 individuals were required to measure the prevalence with an absolute precision of $5 \%$, $10 \%$ non-response and 1.5 design effect (to account for clustering within household). We assumed design effect at household level to be 1.5 as previous studies from India did not report ntracluster correlation coefficient (ICC) at the household level required for calculation of exact design effect. The selection of villages was by convenient sampling. We randomly sampled $35 \%$ of the households with older adults from the electoral list stratified by village that yielded 689 individuals from 532 households.

\section{Data collection}

We conducted face-to-face interviews at their households between February 2019 and April 2019 using pretested questionnaire. The questionnaire was administered in Tamil, the local language. We measured handgrip strength using handheld dynamometer (CAMRY 200 Lbs/90 kgs Digital Hand Dynamometer), height using ultrasonic stadiometer (CAMRY MCP Handheld Ultrasonic Stadiometer) and weight using calibrated weighing scale (Hesley Inc). All measurements were administered by a single field investigator (KK) who was trained in measuring all parameters in a standardised manner.

\section{Definition and assessment of frailty}

Frailty was measured using validated tools from the three definitions of frailty. Fried's Phenotype (FP) and Frailty Index (FI) were chosen because they were extensively used in literature. ${ }^{14}$ Tilburg Frailty Indicator (TFI) was chosen based on its favourable psychometric properties. ${ }^{15}$ The list of variables collected and scoring for each of the definition is provided in online supplementary file 1 .

Physical definition of frailty: FP is a five-item questionnaire with components including shrinking, exhaustion, low physical activity, slowness and weakness. Each of the component was scored as 0 or 1 as per Cardiovascular Health Study (CHS) criteria. ${ }^{1}$ Frail score was an unweighted sum of the components and ranged from 0 to 5. Participants were categorised into three categories; frail (3 to 5), pre-frail (1 to 2 ) and robust (0).

Accumulation of deficits: FI was constructed using 40 deficit variables from eight domains namely general health, medically diagnosed conditions, medical symptoms, functional activities assessment, ADLs, Body Mass Index (BMI), grip strength and gait speed. ${ }^{2}$ The index score ranged from 0 to 1 . The participants were classified into two categories; robust if score was less than 0.2 and frail if the score ranged between 0.2 to 1.0. Instead of 70-item Frailty Index, we used 40-item tool so as not to overburden the participants.

Multi-domain definition of frailty: TFI is a 15 -item self-reported questionnaire comprising physical, psychological and social component. ${ }^{3}$ Frail category was calculated by an unweighted sum of the domain scores and the score ranged from 0 to 15 . Participants were categorised into two categories; frail if the score ranged between 5 and 15 and not frail (0 to 4$)$.

\section{Falls}

Falls in the last 1 year was measured using a single item question 'Did you ever fall down in the past year?' The response was dichotomised as no fall versus one or more falls.

\section{Fear of falling}

Short Falls Efficacy Scale tool, a 7-item questionnaire, was used to measure fear of fall. ${ }^{16}$ Total score ranged from 7 


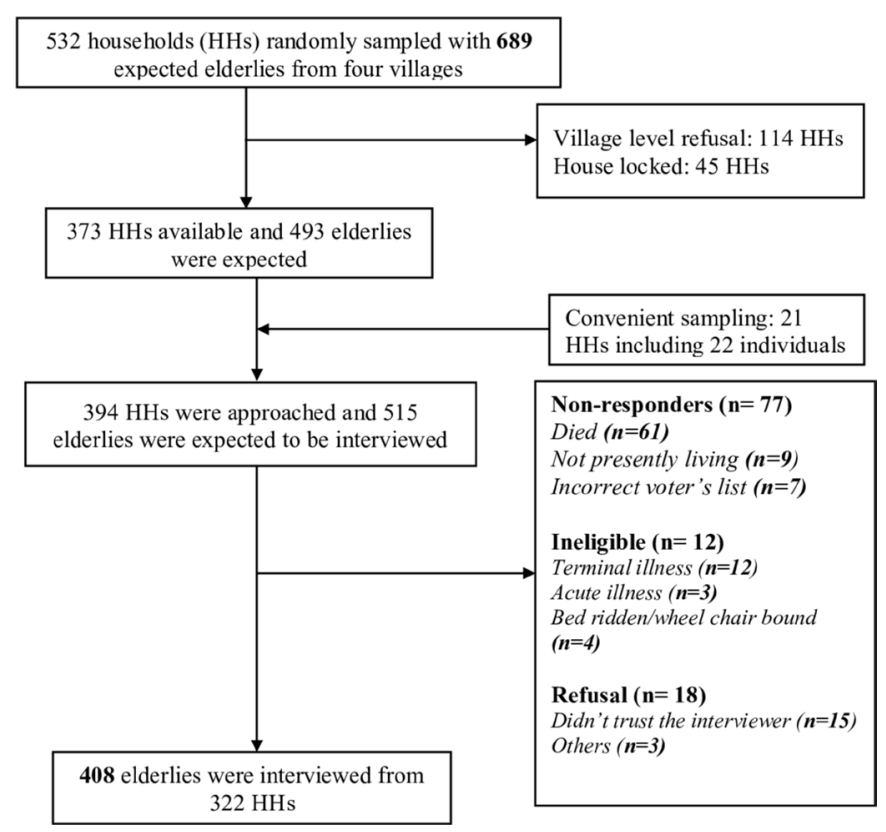

Figure 1 Demographic characteristics of study participants.

to 28 (no concern to high concern) that was categorised into three groups namely low concern of falling ( 7 to 8 ), moderate concern of falling (9 to 13) and high concern of falling (14 to 28).

\section{Statistical analyses}

We performed data processing and statistical analysis using Stata 14 (StataCorp, USA). We derived socioeconomic scores (SES) using Principle Component Analysis (PCA) technique ${ }^{17}$ using household assets and dwelling characteristics. The SES scores were categorised into tertiles (poor, middle income and rich). Unweighted and weighted (for non-response, poststratification for sex) prevalence estimates were reported along with 95\% CI after taking clustering at household level and stratified sampling by village (using survey (.svy) command in Stata).

We considered a priori, socio-demographic determinants of frailty that included age, gender, ${ }^{18}$ socioeconomic status, ${ }^{19}$ education, nature of their routine work, ${ }^{20}$ living arrangement ${ }^{21}$ and alcohol consumption ${ }^{22}$ based on the plausible relevance to the outcome from previous literature. For FP, a multinomial logistic regression was used as the proportional odds assumption underlying ordinal logistic regression model was not valid. We report, OR with 95\% CI after testing for Independence of Irrelevant Alternatives (IIA) assumption. For the other two tools (FI and TFI) binary logistic regressions were performed.

We used binary logistic regression to estimate the association (OR with $95 \% \mathrm{CI}$ ) of frailty on history of falls. An ordinal logistic regression was used to estimate the effect of frailty as an exposure with fear of falling (ordinal outcome). We report OR with $95 \% \mathrm{CI}$ after testing for the proportional odds assumption. For all analyses, robust SE was used to account for clustering at household level and village was added as one of the independent variable to take stratified sampling into account. Goodness of fit was tested using Hosmer-Lemeshow test. All statistical tests used a two-sided hypothesis with significance level set at 0.05 .

\section{Patient and public involvement}

We did not involve any elderly community-dwelling individuals or patients while developing the research question. However, when the tool and the logistics of data collection was pilot tested, we took feedback from the elderly living in the community. The study results are not planned to be disseminated to the participants, but the anthropometric, blood pressure, grip strength and BMI readings taken during the survey were provided to the participants.

\section{RESULTS}

\section{Socio-demographic characteristics}

Out of 689 randomly selected participants, 408 participants completed the interview (figure 1) and were included in the analysis (response rate 60\%). The average older people per household in the study was 1.2. The mean age was 67.5 years (SD 6.62), BMI 22.3 (SD 4.8) with slightly higher proportion of women $(56.9 \%)$ and higher proportion of them living alone compared with men. Among the study participants, $38.8 \%$ had a fall at least once in the past year of which one-fifth $(20.4 \%)$ of the participants experienced a fracture due to the fall. Almost half (48.3\%) of the participants had high concern of falling (table 1).

\section{Prevalence of frailty}

The unweighted prevalence of frailty as per physical definition (FP), accumulation of deficits (FI) and multi-domain definition (TFI) was $25.9 \%$ (95\% CI: 21.9 to 30.5), $62.5 \%$ (95\% CI: 57.7 to 67.1 ) and $62.7 \%$ (95\% CI: 57.9 to 67.3$)$, respectively. The weighted prevalence of frailty (accounted for non-response and poststratification to adjust for sex distribution) for FP, FI and TFI was $27.6 \%$ (95\% CI: 18.9 to 28.1 ), $59.2 \%$ (95\% CI: 53.9 to 64.3 ) and $62.6 \%$ (95\% CI: 57.4 to 67.6 ), respectively. Though the response rate was $60 \%$, there were no differences in the characteristics (age and gender) between responders and non-responders. Despite the high non-response rate $(40 \%)$, the weighted and unweighted estimates were almost similar (online Supplementary figure -1 ). We excluded the 21 participants who were interviewed through convenient sampling and the prevalence estimates were not affected (data not shown).

The prevalence of frailty was higher among women compared with men irrespective of definitions (figure 2). The unconditional ICC at household level (with an average cluster size of 1.2) for frailty using FP, FI and TFI was 0.051 (95\% CI: 0.000 to 0.993$), 0.086$ (95\% CI: 0.002 to 0.775 ) and 0.125 (95\% CI: 0.010 to 0.681 ). The proportion of agreement between FP and FI was 58\%. 
Table 1 Demographic characteristics of the participants

\begin{tabular}{|c|c|c|c|}
\hline & Overall & Male & Female \\
\hline & $n=408$ & $n=176$ & $\mathrm{n}=\mathbf{2 3 2}$ \\
\hline Characteristics & $\mathrm{n}=322 \mathrm{HHs}$ & $\mathrm{n}=167 \mathrm{HHs}$ & $\mathrm{n}=155 \mathrm{HHs}$ \\
\hline Age (mean, SD) & $67.52 \pm 6.62$ & $66.55 \pm 6.58$ & $66.73 \pm 6.56$ \\
\hline \multicolumn{4}{|l|}{ Religion (N, \%) } \\
\hline Hindu & 265 (82.3) & $130(77.84)$ & $135(87.10)$ \\
\hline Christian & 48 (14.9) & $29(17.37)$ & $19(12.26)$ \\
\hline \multicolumn{4}{|l|}{ Socioeconomic status* (N, \%) } \\
\hline Rich & $141(34.56)$ & $66(37.50)$ & 75 (32.33) \\
\hline Middle category & $136(33.33)$ & $66(37.50)$ & $70(30.17)$ \\
\hline Poor & $131(32.11)$ & $44(25.00)$ & $87(37.50)$ \\
\hline \multicolumn{4}{|l|}{ Marital status (N, \%) } \\
\hline Married & $159(49.38)$ & $131(78.44)$ & $28(18.06)$ \\
\hline Widow/widower & $163(50.62)$ & $36(21.56)$ & $127(81.94)$ \\
\hline \multicolumn{4}{|l|}{ Living arrangement (N, \%) } \\
\hline Children/other family & $184(57.14)$ & $91(54.49)$ & $93(60.0)$ \\
\hline With spouse only & $71(22.05)$ & $61(36.53)$ & $10(6.45)$ \\
\hline Alone & $67(20.81)$ & $15(8.98)$ & $52(33.55)$ \\
\hline \multicolumn{4}{|l|}{ Education level (n, \%) } \\
\hline Upper secondary/graduate & $41(10.05)$ & $34(19.32)$ & 7 (3.02) \\
\hline Lower secondary & $83(20.34)$ & $35(19.89)$ & $48(20.69)$ \\
\hline No formal education/primary & $284(69.61)$ & $107(60.80)$ & $177(76.29)$ \\
\hline \multicolumn{4}{|l|}{ Employment status (n, \%) } \\
\hline Salaried & $5(1.70)$ & $3(1.70)$ & $2(0.86)$ \\
\hline Self-employed & $293(71.81)$ & $138(78.41)$ & $155(66.81)$ \\
\hline Retired with pension & $26(6.37)$ & $22(12.50)$ & $4(1.72)$ \\
\hline Currently not working & $31(7.60)$ & $13(7.39)$ & $18(7.76)$ \\
\hline Never worked for money & $53(12.99)$ & - & $53(22.84)$ \\
\hline \multicolumn{4}{|l|}{ Physical activity in daily routine $(\mathrm{n}, \%)$} \\
\hline Strenuous physical labour & $89(21.81)$ & $32(18.18)$ & $57(24.57)$ \\
\hline Moderate physical activity & $219(53.68)$ & $80(45.45)$ & $139(59.91)$ \\
\hline Some physical activity & $67(16.42)$ & $42(23.86)$ & $25(10.78)$ \\
\hline Desk job with no or minimal & $33(8.09)$ & $22(12.50)$ & $11(4.74)$ \\
\hline BMI (mean, SD) & $22.3 \pm 4.8$ & $21.9 \pm 4.6$ & $22.6 \pm 4.9$ \\
\hline \multicolumn{4}{|l|}{ Smoking status (n, \%) } \\
\hline Never used & $147(36.03)$ & $45(25.57)$ & $102(43.97)$ \\
\hline Have used in past & $29(7.11)$ & $21(11.93)$ & $8(3.45)$ \\
\hline Smoke/smokeless form of tobacco & $232(56.86)$ & $110(62.50)$ & $122(52.59)$ \\
\hline \multicolumn{4}{|l|}{ Alcohol consumption (n, \%) } \\
\hline Never used & $289(70.83)$ & $61(34.66)$ & 228 (98.28) \\
\hline Have used in past & $36(8.82)$ & $33(18.75)$ & $3(1.29)$ \\
\hline Currently using & $83(20.34)$ & $82(46.59)$ & $1(0.43)$ \\
\hline \multicolumn{4}{|l|}{ Current comorbidities (n, \%) } \\
\hline Arthritis & $116(28.43)$ & $37(21.02)$ & 79 (34.10) \\
\hline Stroke & $11(2.70)$ & $4(2.27)$ & 7 (3.02) \\
\hline Angina & 60 (14.71) & 27 (15.34) & 33 (14.22) \\
\hline
\end{tabular}


Table 1 Continued

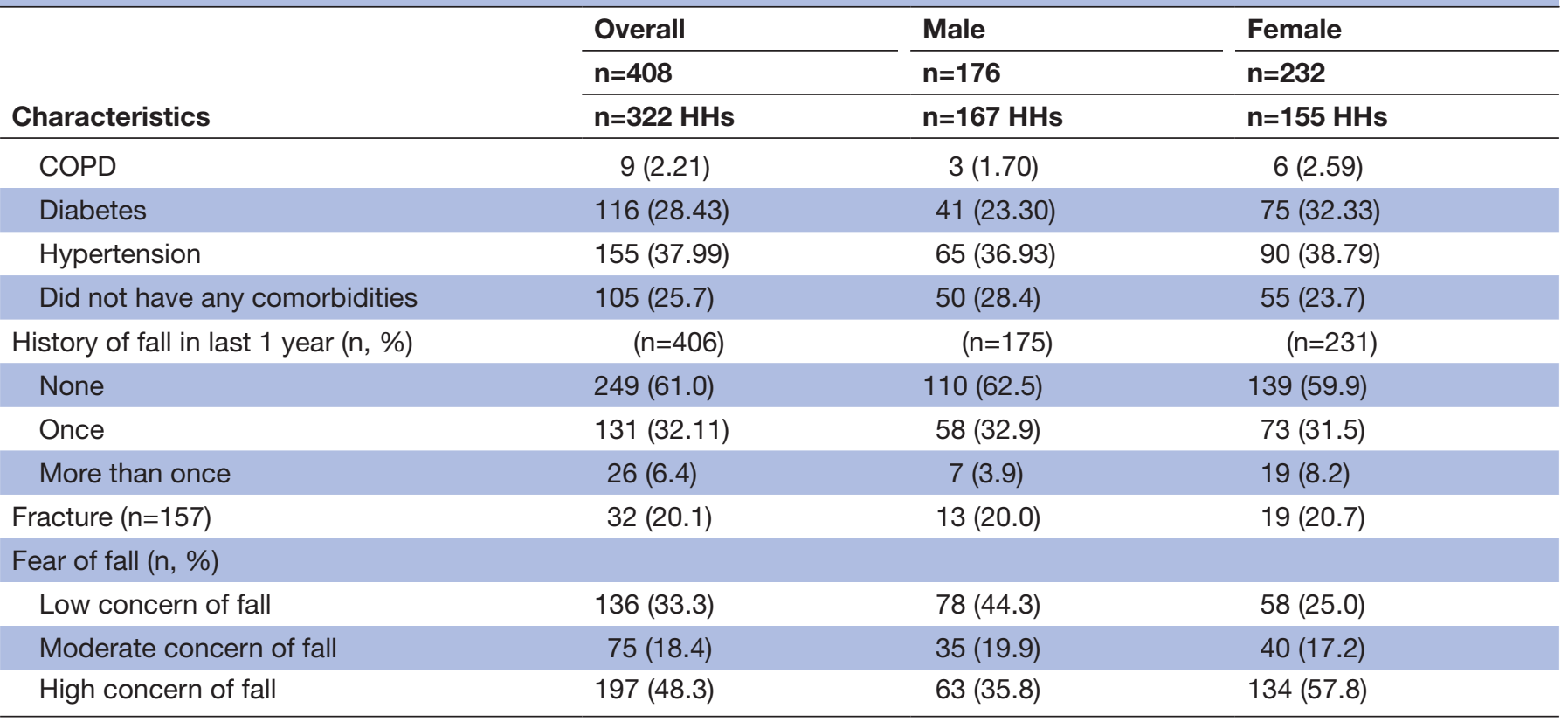

*Socioeconomic scores were derived using principle component analysis technique using household assets and dwelling characteristics. The scores were categorised into tertiles.

BMI, Body Mass Index; COPD, Chronic Obstructive Pulmonary Disease; HHs, households; n, number of individuals.

Agreement between FP and TFI was 59\% whereas agreement between FI and TFI was $80 \%$.

\section{Determinants of frailty}

Factors associated with frailty - physical definition (FP)

In the adjusted analysis, the odds of being frail was significantly higher by 1.9 times with every 5 years increase in age (online Supplementary table -1 ). The odds of frailty were independently higher with no formal education (OR 2.83, 95\% CI: 1.38 to 5.79), poorer SES (OR 3.55,

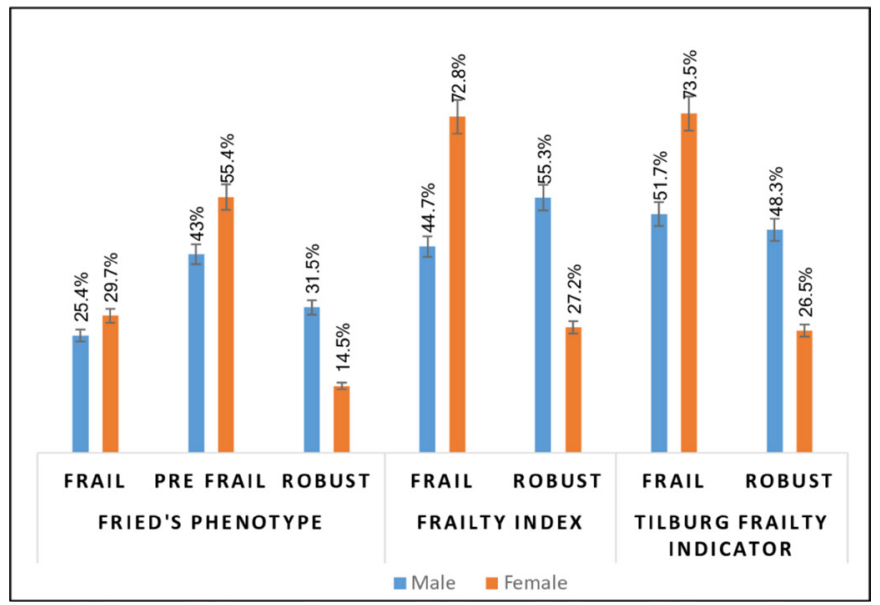

Figure 2 Weighted prevalence of frailty by gender for the three definition of frailty. Unconditional ICC for frailty in FP, FI and TFI were 0.051 (95\% Cl: 0.000 to 0.993$), 0.086$ (95\% Cl: 0.002 to 0.775$)$ and $0.125(95 \% \mathrm{Cl}: 0.010$ to 0.681 ), respectively. FI, Frailty Index; FP, Fried's Phenotype; ICC, intracluster correlation coefficient; TFI, Tilburg Frailty Indicator.
95\% CI: 1.30 to 9.68 ) and routine work with minimum physical effort (OR 2.52, 95\% CI: 1.12 to 5.67 ). Figure 3A displays the ORs of pre-frailty and frailty for all the factors considered in the regression model.

Factors associated with frailty - accumulation of deficits (FI) The odds of frailty significantly increased by 1.51 times with every 5 years increase in age (95\% CI: 1.20 to 1.89 ). Female and minimum physical activity in routine work were independently associated with increased odds of frailty (figure 3B) (online Supplementary table - 2).

Factors associated with frailty - multi-domain definition (TFI) The odds of frailty were independently higher with every 5 years increase in age, in female and those with no formal education (figure 3B) (online Supplementary table - 3).

\section{Association of frailty and falls}

The odds of falling were statistically significantly higher among the frail elderly when compared with the robust elderly after adjusting for age, gender, alcohol, fear of falls and living arrangement across the frailty definitions (table 2).

\section{Association of frailty and fear of falling}

The odds of fear of falling was statistically significantly higher among the frail elderly when compared with the non-frail/robust elderly in all the frailty models after adjusting for age, gender, living arrangement, history of falls and alcohol consumption (table 3). Higher age, female sex and history of falls were independently associated with fear of falling. 


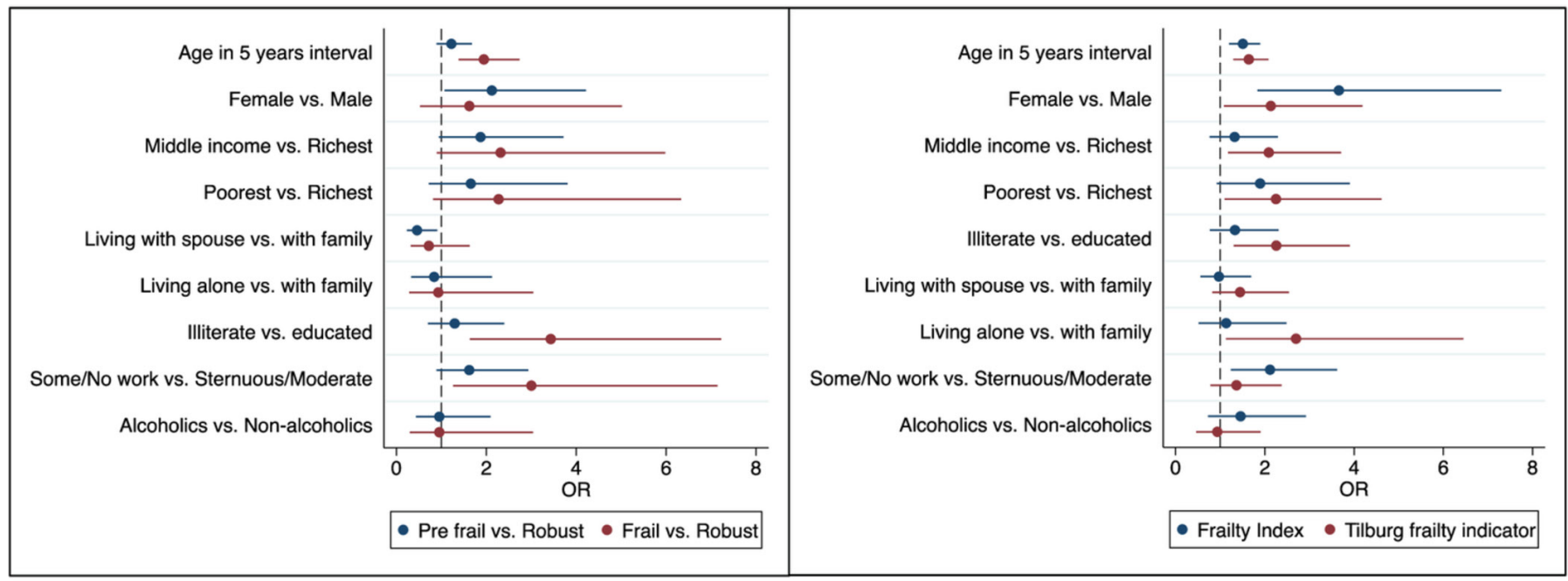

Panel - 3a

Panel - 3b

Figure 3 Panel - 3a: Determinants of pre-frailty and frailty defined by physical definition (FP). Panel - 3b: Determinants of frailty defined by accumulation of deficits (FI) and multi-domain definition (TFI). FI, Frailty Index; FP, Fried's Phenotype; TFI, Tilburg Frailty Indicator.

\section{DISCUSSION}

\section{Summary of key findings}

The prevalence of frailty among the community-dwelling older people in rural Southern India was $28 \%$ using physical definition of frailty (FP), $62 \%$ using accumulation of deficits (FI) and $64 \%$ using multi-domain definition of frailty (TFI). FI and TFI had a good agreement (80\%). Increase in age, no formal education, poor SES and routine work with minimum physical activity were significantly associated with higher odds of frailty defined by FP. While in FI, factors like increase in age, female and minimum physical activity in routine work were significantly associated with frailty. In TFI model, increase in age, female gender, and no formal education were significantly associated with increased odds of frailty. In FP model, gender was not significantly associated with frailty but showed a positive trend of association. Education and SES had shown a positive trend but not significant association in FI model. In TFI model, determinants like living alone and minimum physical activity in routine work shown a positive trend. With higher sample size, these factors might show a significant association with frailty. Frail older adults were more likely to report falls and fear of falling compared with robust older adults.

There are several strengths of this study. Households were selected by simple random sampling method hence minimising selection bias. Although the response rate was $60 \%$, there were no differences in the characteristics (age and sex) of the non-responders and responders. The non-response rate was high particularly in one village due to cultural inhibition. A single investigator performed all the anthropometric measurements and conducted the household survey that might minimise the measurement error. This study is unique as we compared the prevalence of frailty measured using three definitions in the same sample.

\section{Comparison with existing literature}

Prevalence of frailty

Physical definition of frailty (FP): The prevalence of frailty in our study was $28 \%$ (95\%CI: 24.0 to 33.0 ) which was

Table 2 Association of frailty (defined by three definitions) and falls

\begin{tabular}{|c|c|c|c|c|c|c|}
\hline \multirow[b]{3}{*}{ Falls } & \multicolumn{3}{|c|}{ Crude analysis } & \multicolumn{3}{|c|}{ Adjusted analysis* } \\
\hline & \multicolumn{3}{|c|}{$(n=406)$} & \multicolumn{3}{|c|}{$(n=406)$} \\
\hline & OR & $95 \% \mathrm{Cl}$ & $P$ value & OR & $95 \% \mathrm{Cl}$ & $P$ value \\
\hline Physical definition (FP) & & & $<0.001$ & & & 0.05 \\
\hline Robust & 1 & 1 & & 1 & 1 & \\
\hline Pre-frail & 2.47 & 1.42 to 4.31 & & 1.94 & 1.04 to 3.59 & \\
\hline Frail & 3.72 & 2.03 to 6.81 & & 2.33 & 1.13 to 4.80 & \\
\hline Accumulation of deficits (FI) & 2.51 & 1.64 to 3.87 & $<0.001$ & 1.77 & 1.04 to 3.00 & 0.04 \\
\hline Multi-domain (TFI) & 2.64 & 1.70 to 4.11 & $<0.001$ & 1.86 & 1.10 to 3.14 & 0.02 \\
\hline
\end{tabular}

${ }^{*}$ Adjusted for age, gender, alcohol, fear of falls, living arrangement, nature of routine work and village.

FP, Fried's Phenotype; FI, Frailty Index; TFI, Tilburg Frailty Indicator. 


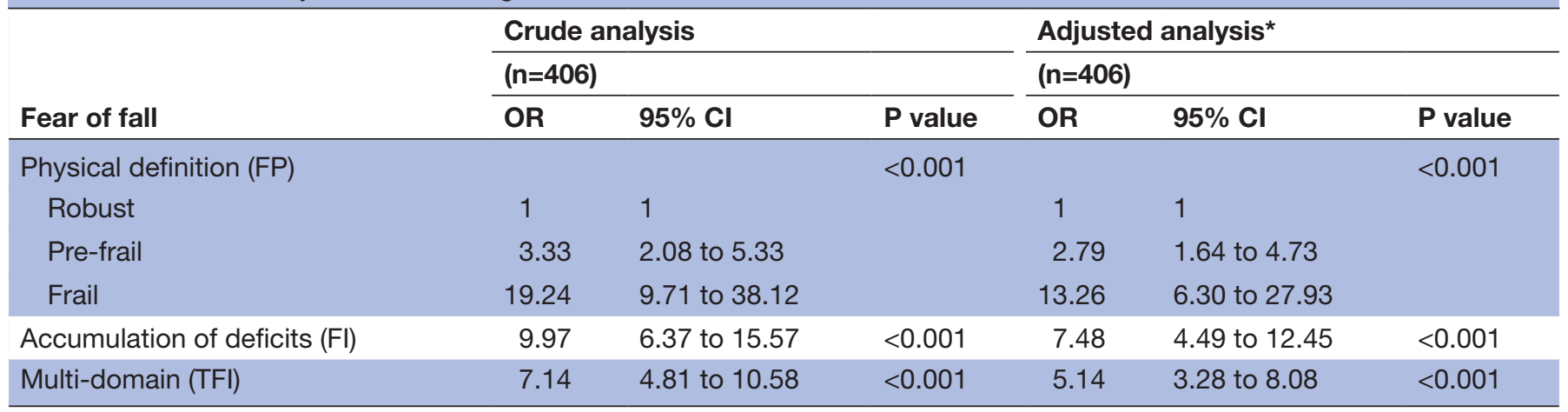

*Adjusted for age, female, falls, alcohol, living arrangement, nature of routine work and village.

FP, Fried's Phenotype; FI, Frailty Index; TFI, Tilburg Frailty Indicator.

similar to the prevalence estimates (26\%, $95 \%$ CI: 20.5 to 31.5) from a cross-sectional study conducted in an urban city in Western India. ${ }^{11}$ Another cross-sectional study conducted in urban cities of Southern India reported prevalence of $11.4 \%$ (95\% CI: 9.1 to 13.7 ) ${ }^{13}$ However, in this study authors excluded grip strength while defining frailty that could have underestimated the prevalence. A recent cross-sectional study among the rural elderly from Sri Lanka using CHS criteria for defining frailty had reported a prevalence of $34.6 \%$ (95\% CI: 29.3 to 40.4), which is almost similar to our study findings. ${ }^{23}$

Accumulation of deficits (FI): The prevalence of frailty in our study defined by this index was $62 \%$ (95\% CI: 56.4 to 66.4). A large multi centric study from India $(n=7150)$ with a national representative sample reported a prevalence of $57 \%$ (95\% CI: 54.4 to 59.4) which supports our findings. ${ }^{12}$

Multi-domain definition of frailty (TFI): The prevalence of frailty was $64 \%$ (95\%CI: 59.3 to 69.1 ). We could not find any published report from India or any of the neighbouring countries using this tool. However, a study conducted among the community-dwelling elderly in Netherlands reported a prevalence of $40.2 \%$ (95\%CI: 31.0 to 50.0) ${ }^{24}$ But the prevalence percentage cannot be compared with our study results due to the variation in the study population, setting and ethnicity. Hence, it is reasonable to conclude that prevalence of frailty is higher in India, compared with other low-income and middle-income countries (LMICs) irrespective of its definition. ${ }^{25}$

\section{Agreement between the tools}

Given that each definition measures various domains of frailty, it is crucial to compare the studies that use tools that agree well with each other. We found a good agreement $(80 \%)$ between FI and TFI. The proportion of agreement between FP with FI and TFI was 58\% and $59 \%$, respectively. Therefore, the prevalence estimates measured using FI and TFI may be comparable.

\section{Clustering of frailty by household}

It can be argued that the frailty could be related to the household characteristics and elderly living in the same household could have similar risk of frailty. Out of 322 households, there were 86 households from which more than one older adult participated in the study. The unconditional ICC for frailty defined using TFI was 0.125 (95\% CI: 0.010 to 0.681 ). However, the ICC was closer to zero after adjusting for SES of the household suggesting the role of SES of HH in this condition. This finding is important while planning for community-based interventions towards reducing frailty.

\section{Factors associated with frailty}

Age and frailty: Age is a well-known risk factors of frailty. ${ }^{18}$ We found a positive association between age and frailty across the three definitions which is similar to the cross-sectional studies from India ${ }^{11-13}$ and a recent systematic review of 21 cohort studies from high-income countries (HICs). ${ }^{18}$ The influence of ageing on frail syndrome is related due to the decline in the physiological reserve with ageing ${ }^{26}$ and other age-related pathological conditions. ${ }^{1}$ Even though ageing is a risk factor for frailty, not all older people are frail ${ }^{27}$ suggesting that the onset of frailty requires other reasons for augmenting this condition than normative process of ageing. ${ }^{28}$

Sex and frailty: Women had higher prevalence of frailty compared to men after adjusting for potential confounders. This is similar to a cross-sectional study from India that showed twice the odds of frailty in women compared with men. ${ }^{12}$ A recent systematic review of cohort studies reported both positive $\mathrm{e}^{29}$ and no association $^{31} 32$ with gender. Higher prevalence of frailty among women may be due poor grip strength, lower average amounts of lean body mass and increased risk of sarcopenia compared with men. ${ }^{33}$

Education, SES and frailty: The prevalence of frailty is higher in lower education level and this finding is similar to the findings from cross-sectional studies. ${ }^{11} 34$ We observed a positive but non-significant association between frailty and lower education level in the accumulation of deficits definition. But a study from India using the same definition reported education as one of the protective factors of frailty. ${ }^{12}$ The non-significant 
association may be due to the smaller proportion (30\%) of educated participants in our study compared with the other study from India (53\%). The prevalence of frailty was higher among poorer compared with richest SES which corroborates with the findings of the studies from India $^{1112}$ and a systematic review of cohort studies from HICs. ${ }^{18}$ Though education and income do not have a direct impact in the pathophysiology of frailty, it might interfere in the individual's lifestyle that could influence the frailty progression. ${ }^{35}$

Physical activity in routine work and frailty: We found that moderate-to-strenuous physical activity in routine work as a protective factor of frailty among elderly. This finding is reinforced by the many cross-sectional studies. ${ }^{11} 23$ However, the directionality of this association cannot be deciphered due to cross-sectional nature of the studies.

\section{Frailty, falls and fear of falling}

Falls and fear of falling are interdepended problems and their directionality is not clear. ${ }^{36}$ Both fall and fear of falling has a complex aetiology with frailty. It is hypothesised that chronic diseases and polypharmacy in the elderly lead to develop anxiety and fear of falling which in turn cause imbalance in gait and leading to falls. ${ }^{37-39}$ Many older adults who fall develop a fear of falling, despite of the injury/fracture, that may lead to restricted activity in daily routine, dependency for ADLs, social isolation, depression and increased risk of future falls. ${ }^{40}$ Across the frailty definitions, we found that the frail elderly were at 1.8 times higher risk of falls compared with the robust elderly. To the best of our knowledge, there were no studies neither from India nor from the neighbouring LMIC countries studying the association of frailty on falls. However, a meta-analysis of 10 cohort studies from HICs concluded that frailty is a significant risk factor of future falls among community-dwelling elderly. ${ }^{41}$

After adjusting for the major confounders (age, gender, falls, alcohol and living arrangement), we found that odds of fear of falling was higher among the frail participants compared with the robust irrespective of the frailty models. Previous study from India hypothesised fear of falling as a determinant of frailty and concluded that odds of frailty were higher among the participants with fear of falling compared with those not having fear of falling. ${ }^{11}$ Directionality of this association cannot be derived from these cross-sectional studies and cohort studies are needed to comment on the causality.

Given the higher prevalence of frailty and its association with falls and fear of falling, it is important to identify frailty among elderly. ${ }^{42}{ }^{43}$ Since, frailty is a reversible condition, early screening in primary care centre is recommended and the provision of the preventative interventions like nutrition fortification, physical exercise programme, cognitive treatment or combination of these can help in reversing frailty. ${ }^{9}$ A recent systematic review reported the aforementioned interventions targeted for frailty were also associated with lowered risk of falls among older adults. ${ }^{44}$

\section{Limitations of the study}

The findings of our study should be viewed in light of certain limitations. Lack of validation of frailty assessment tools specific to the Indian population is one of the key limitations. Cognition an important determinant of frailty which was not measured in the study. Critical items in the frailty assessment tools were self-reported that might have led to imprecision. Causality of frailty due to socio-demographic characteristics cannot be established because of cross-sectional design. Though we could not meet the target sample size of 625 , the prevalence estimates were reasonably precise but may be underpowered for the regression analyses. Finally, our study included only rural community dwelling elderly who were predominantly engaged in agricultural activities. Therefore, the study results are not likely generalisable to other settings.

\section{Implications on future research}

In India, frailty is less explored. Due to geographical diversity in India, we need more studies to derive a national representative prevalence of frailty. Future studies are recommended to validate the frailty measuring tools in Indian settings. Since frailty is a dynamic condition, there is a need to develop a community based interventions including physical activity, nutrition fortification and cognitive therapy to treat frail elderly that is suitable to Indian social and cultural context. Future prospective research is recommended in Indian context to assess the effectiveness of interventions evaluated in Western population, in reducing falls or improving routine activities among frail older population.

\section{Conclusion}

The prevalence of frailty in the rural Thanjavur of South India is higher in comparison with LMICs and HICs. Factors associated with frailty are age, gender, socioeconomic status, physical activity in routine work and education level. Understanding the modifiable risk factors of frailty can provide a valuable reference for future prevention and intervention.

Contributors ND and KK conceived and designed the study. KK collected the data. ND and KK analysed the data. KK wrote the first draft of the manuscript. ND critically revised the manuscript. Both authors agreed to the final version.

Funding This is a non-funded study completed as a part of KK Master's thesis at the Indian Institute of Public Health - Delhi (IIPH - D) and degree awarded by Academy of Scientific and Innovative Research (AcSIR).

Competing interests None declared.

Patient consent for publication Not required.

Ethics approval The study protocol was approved by the Institutional Ethics Committee of Indian Institute of Public Health - Delhi (IIPHD_IEC_S_51_2018).

Provenance and peer review Not commissioned; externally peer reviewed.

Data availability statement Data are available upon reasonable request.

Open access This is an open access article distributed in accordance with the Creative Commons Attribution Non Commercial (CC BY-NC 4.0) license, which permits others to distribute, remix, adapt, build upon this work non-commercially, and license their derivative works on different terms, provided the original work is properly cited, appropriate credit is given, any changes made indicated, and the use is non-commercial. See: http://creativecommons.org/licenses/by-nc/4.0/. 


\section{REFERENCES}

1 Fried LP, Tangen CM, Walston J, et al. Frailty in older adults: evidence for a phenotype. J Gerontol A Biol Sci Med Sci 2001;56:M146-56.

2 Rockwood K, Stadnyk K, MacKnight C, et al. A brief clinical instrument to classify frailty in elderly people. The Lancet 1999;353:205-6.

3 Gobbens RJJ, van Assen MALM, Luijkx KG, et al. The predictive validity of the Tilburg frailty indicator: disability, health care utilization, and quality of life in a population at risk. Gerontologist 2012:52:619-31.

4 Schuurmans $\mathrm{H}$, Steverink $\mathrm{N}$, Lindenberg $\mathrm{S}$, et al. Old or frail: what tells us more? J Gerontol A Biol Sci Med Sci 2004;59:M962-5.

5 Cigolle CT, Ofstedal MB, Tian Z, et al. Comparing models of frailty: the health and retirement study. J Am Geriatr Soc 2009;57:830-9.

6 Vermeiren S, Vella-Azzopardi R, Beckwée D, et al. Frailty and the prediction of negative health outcomes: a meta-analysis. J Am Med Dir Assoc 2016;17:1163.e1-17.

7 CDC. Important Facts about Falls | Home and Recreational Safety | CDC Injury Center [Internet], 2019. Available: https://www.cdc.gov/ homeandrecreationalsafety/falls/adultfalls.html [Accessed 10 Jun 2019].

8 Santos-Eggimann B, Sirven N. Screening for frailty: older populations and older individuals. Public Health Rev 2016;37:7.

9 Apóstolo J, Cooke R, Bobrowicz-Campos E, et al. Effectiveness of interventions to prevent pre-frailty and frailty progression in older adults. JBI Database System Rev Implement Rep 2018;16:140-232.

10 United Nations Population Fund. Caring for our Elders: Early Response" - India Aging Report - 2017. New Delhi, India: UNFPA, 2017.

11 Kashikar, Yashoda N. Prevalence and determinants of frailty in older adults in India. Indian Journal of Gerontology 2016;30:364-81.

12 Biritwum RB, Minicuci N, Yawson AE, et al. Prevalence of and factors associated with frailty and disability in older adults from China, Ghana, India, Mexico, Russia and South Africa. Maturitas 2016;91:8-18.

13 AT J, Bryce R, Prina M, et al. Frailty and the prediction of dependence and mortality in low- and middle-income countries: a 10/66 population-based cohort study. BMC Med 2015;13:138.

14 Buta BJ, Walston JD, Godino JG, et al. Frailty assessment instruments: systematic characterization of the uses and contexts of highly-cited instruments. Ageing Res Rev 2016;26:53-61.

15 Sutton JL, Gould RL, Daley S, et al. Psychometric properties of multicomponent tools designed to assess frailty in older adults: a systematic review. BMC Geriatr 2016;16:55.

16 Kempen GIJM, Yardley L, Van Haastregt JCM, et al. The short FES-I: a shortened version of the falls efficacy scale-international to assess fear of falling. Age Ageing 2008;37:45-50.

17 Vyas S, Kumaranayake L. Constructing socio-economic status indices: how to use principal components analysis. Health Policy Plan 2006;21:459-68.

18 Feng Z, Lugtenberg M, Franse C, et al. Risk factors and protective factors associated with incident or increase of frailty among community-dwelling older adults: a systematic review of longitudinal studies. PLoS One 2017;12:e0178383.

19 Hoogendijk EO, van Hout HPJ, Heymans MW, et al. Explaining the association between educational level and frailty in older adults: results from a 13-year longitudinal study in the Netherlands. Ann Epidemiol 2014;24:538-44.

20 Rogers NT, Marshall A, Roberts $\mathrm{CH}$, et al. Physical activity and trajectories of frailty among older adults: evidence from the English longitudinal study of ageing. PLoS One 2017;12:e0170878.

21 Chamberlain AM, St. Sauver JL, Jacobson DJ, et al. Social and behavioural factors associated with frailty trajectories in a population-based cohort of older adults. BMJ Open 2016;6:e011410.
22 Kojima G, Liljas A, Iliffe S, et al. A systematic review and metaanalysis of prospective associations between alcohol consumption and incident frailty. Age Ageing 2018;47:26-34.

23 Siriwardhana DD, Weerasinghe MC, Rait G, et al. Prevalence of frailty in rural community-dwelling older adults in Kegalle district of Sri Lanka: a population-based cross-sectional study. BMJ Open 2019;9:e026314.

24 Metzelthin SF, Daniëls R, van Rossum E, et al. The psychometric properties of three self-report screening instruments for identifying frail older people in the community. BMC Public Health 2010;10:176.

25 Siriwardhana DD, Hardoon S, Rait G, et al. Prevalence of frailty and prefrailty among community-dwelling older adults in low-income and middle-income countries: a systematic review and meta-analysis. BMJ Open 2018;8:e018195.

26 Alvis BD, Hughes CG. Physiology considerations in geriatric patients. Anesthesiol Clin 2015;33:447-56.

27 Bergman H, Ferrucci L, Guralnik J, et al. Frailty: An Emerging Research and Clinical Paradigm--Issues and Controversies. J Gerontol A Biol Sci Med Sci 2007;62:731-7.

28 Fulop T, Larbi A, Witkowski JM, et al. Aging, frailty and age-related diseases. Biogerontology 2010;11:547-63.

29 Ottenbacher KJ, Graham JE, Al Snih S, et al. Mexican Americans and frailty: findings from the Hispanic established populations epidemiologic studies of the elderly. Am J Public Health 2009;99:673-9.

30 Myers V, Drory Y, Goldbourt U, et al. Multilevel socioeconomic status and incidence of frailty post myocardial infarction. Int $J$ Cardiol 2014;170:338-43.

31 Aranda MP, Ray LA, Snih SA, et al. The protective effect of neighborhood composition on increasing frailty among older Mexican Americans. J Aging Health 2011;23:1189-217.

32 McHugh JE, Dowling M, Butler A, et al. Psychological distress and frailty transitions over time in community-dwelling older adults. Ir J Psychol Med 2016;33:111-9.

33 Cesari M, Landi F, Vellas B, et al. Sarcopenia and physical frailty: two sides of the same coin. Front Aging Neurosci 2014;6.

34 Gobbens RJJ, van Assen MALM. Explaining frailty by lifestyle. Arch Gerontol Geriatr 2016;66:49-53.

35 Mello AdeC, Engstrom EM, Alves LC. Health-Related and sociodemographic factors associated with frailty in the elderly: a systematic literature review. Cad Saúde Pública 2014;30:1143-68.

36 Friedman SM, Munoz B, West SK, et al. Falls and fear of falling: which comes first? A longitudinal prediction model suggests strategies for primary and secondary prevention. J Am Geriatr Soc 2002;50:1329-35.

37 Senthil Kumar R, Ravindran K. A cross sectional study on the prevalence and risk factors of fall among the elderly in an urban slum in Chennai. International Journal Of Community Medicine And Public Health 2019;6:1102-7.

38 Liu JYW. Fear of falling in robust community-dwelling older people: results of a cross-sectional study. J Clin Nurs 2015;24:393-405.

39 Hammond T, Wilson A. Polypharmacy and falls in the elderly: a literature review. Nurs Midwifery Stud 2013;1:171-5.

40 Boyd R, Stevens JA. Falls and fear of falling: burden, beliefs and behaviours. Age Ageing 2009;38:423-8.

41 Cheng $\mathrm{M}-\mathrm{H}$, Chang S-F. Frailty as a risk factor for falls among community Dwelling people: evidence from a meta-analysis. J Nurs Scholarsh 2017;49:529-36.

42 Ambagtsheer RC, Beilby JJ, Visvanathan R, et al. Should we screen for frailty in primary care settings? A fresh perspective on the frailty evidence base: a narrative review. Prev Med 2019;119:63-9.

43 Dent E, Lien C, Lim WS, et al. The Asia-Pacific clinical practice guidelines for the management of frailty. J Am Med Dir Assoc 2017;18:564-75.

44 Tricco AC, Thomas SM, Veroniki AA, et al. Comparisons of interventions for preventing falls in older adults: a systematic review and meta-analysis. JAMA 2017;318:1687-99. 